\title{
Accumulation of adverse childhood events and overweight in children: A systematic review and meta-analysis
}

Authors: Leonie K Elsenburg MSc ${ }^{a, b}$, Kim J E van Wijk MSc ${ }^{b}$, Aart C Liefbroer PhD ${ }^{b, a, c}$, Nynke Smidt $\mathrm{PhD}^{\mathrm{a}}$

Affiliation: ${ }^{a}$ Department of Epidemiology, University of Groningen, University Medical Center Groningen, Groningen, the Netherlands; ${ }^{b}$ Netherlands Interdisciplinary Demographic Institute (NIDI-KNAW), The Hague, the Netherlands; 'Department of Sociology, Vrije Universiteit, Amsterdam, the Netherlands.

Keywords: Life events, overweight, obesity, body mass index, children

Running title: Adverse events and childhood overweight

\section{Contact info:}

Leonie K Elsenburg, MSc

Netherlands Interdisciplinary Demographic Institute (NIDI)

Lange Houtstraat 19

2511 CV The Hague

P.O. Box 11650

2502 AR The Hague

E-mail: elsenburg@nidi.nl

Phone number: +31703565250

Word count: 4550

Systematic review registration: PROSPERO, CRD42014014927,

http://www.crd.york.ac.uk/PROSPERO/display_record.asp?ID=CRD42014014927

Funding: This work was supported by a grant of the Graduate School of Medical Sciences of the University Medical Center Groningen awarded to LK Elsenburg and by the multidisciplinary research program Healthy Ageing, Population \& Society (HAPS). HAPS is supported by the University of Groningen.

Disclosure: The authors declared no conflict of interest.

\section{Author contributions:}

L. K. Elsenburg, MSc conceptualized and designed the study, developed the search strategy, conducted the study selection, quality assessment and data-extraction, carried out initial analyses, drafted the initial manuscript, and approved the final manuscript as submitted.

K. J. E. Van Wijk, MSc conducted the study selection, quality assessment and data-extraction, reviewed and revised the manuscript and approved the final manuscript as submitted.

Prof A. C. Liefbroer, PhD conceptualized and designed the study, reviewed and revised the manuscript and approved the final manuscript as submitted. 
N. Smidt, PhD conceptualized and designed the study, provided support with the search strategy, study selection and quality assessment, reviewed and revised the manuscript and approved the final manuscript as submitted.

\section{Study importance questions:}

- No previous systematic review or meta-analysis investigated the relation between the accumulation of adverse life events and overweight in childhood. Previous systematic reviews and meta-analyses have investigated the relation between childhood abuse and (adult) obesity, family functioning and child and adolescent overweight and social stressors and biomarkers of cardiometabolic risk in youth.

- In this study a positive relation between accumulation of adverse life events and overweight measures in childhood is identified.

- This study shows for the first time the wide array of research that is being performed in this research area and provides clear recommendations for future research concerning accumulation of adverse life events and overweight in childhood. In future research, the use of measurement tools specifically designed to assess adverse life events, containing $>10$ events and covering a time period of $\geq 2$ years is recommended. 


\begin{abstract}
Objective: To systematically summarize the evidence of all observational studies investigating the relation between accumulation of adverse life events and measures of overweight in children $<18$ years.

Methods: MEDLINE, EMBASE, PsycINFO and CINAHL were systematically searched (last search date 18 February 2015). The Newcastle-Ottawa Scale was used for methodological quality assessment. Study estimates were pooled using a random-effects model and sources of heterogeneity were explored (PROSPERO reg. nr. CRD42014014927).

Results: Eighteen articles were included, containing five longitudinal ( $n=6361)$ and fourteen cross-sectional and case-control study results $(n=52318)$. The pooled estimate of the longitudinal studies shows that accumulation of adverse life events is positively related to childhood overweight measures $(\mathrm{OR}(95 \% \mathrm{Cl})=1.12(1.01-1.25))$. Cross-sectional and casecontrol study results were heterogeneous. Subgroup analyses show that cross-sectional and case-control studies using a continuous adverse events measure, studies using a continuous overweight measure and studies in children $>6-12$ years generate positive pooled estimates, while the pooled estimate of studies assessing recent adverse events (past 2 years) was indicative of no relation with overweight.

Conclusions: Accumulation of adverse life events and childhood overweight measures are positively associated. However, increases in overweight measures in response to adverse childhood events do not seem to occur instantaneously.
\end{abstract}




\section{Introduction}

At the beginning of this century an estimated $10 \%$ of children in the world had overweight or obesity $^{1}$. Children with overweight or obesity are likely to have overweight or obesity as adults $^{2,3}$. Overweight is related to diseases such as diabetes type 2, cardiovascular disease and cancer and is now one of the leading risk factors to the global burden of disease ${ }^{4-6}$. Although the worldwide increase in childhood overweight and obesity seems to have stabilized, prevalence rates remain high and therefore the threat childhood overweight poses to child as well as adult health has far from disappeared ${ }^{7,8}$. Prevention of childhood overweight is thus warranted.

A growing body of literature acknowledges the role psychosocial stressors, external events or conditions that threaten an individual's well-being, may play in the development of obesity ${ }^{9,10}$. Factors such as problems in the household and poor family functioning (e.g. the division of roles between family members and the level of connectedness, conflict and the quality of communication within the family) have been found to be related to childhood overweight/obesity ${ }^{9,11}$. Low socio-economic status has also been identified as being related to (central) adiposity, overweight and obesity in children ${ }^{12,13}$. Psychosocial stressors are suggested to influence children's weight status via children's health behaviors, such as their physical activity level, dietary intake and sedentary behavior, or via biological processes in the body, such as the stress response or inflammatory processes ${ }^{14-16}$.

Another category of psychosocial stressors that could be of importance in relation to obesity development is adverse childhood events ${ }^{17}$. Adverse childhood events are defined in this study as events (not caused by medication) arising during childhood ( $<18$ years of age) that can threaten the child's mental or physical well-being ${ }^{9,13,18}$. Examples of adverse childhood events are parental divorce, disease or death of a family member, parental incarceration and childhood maltreatment. A distinctive feature of these adverse childhood events in comparison with the earlier mentioned psychosocial stressors is that they bring about a change in the child's life instead of being a (rather) stable aspect of it. To underline that this study is not about (rather) stable aspects, but about relatively abrupt change in the child's life, we have chosen to use the term 'adverse childhood events' instead of the term 'adverse childhood experiences'. Although the latter term 'adverse childhood experiences' is sometimes used to refer to 'adverse childhood events', it is also used to describe chronic exposures to adversity ${ }^{18}$.

Previous systematic reviews and meta-analyses have investigated the relation between childhood abuse and obesity in adult populations ${ }^{19-22}$. These have shown that adults who were abused in childhood had an increased risk of obesity. The relation between childhood abuse and obesity was not identified in children ${ }^{20}$. Accumulation of adverse life events in childhood, such as abuse, separation of parents and mental illness or addiction of a 
household member, also seems to be related to overweight and obesity in adulthood ${ }^{23,24}$. Adverse life events often co-occur and studying the impact of separate childhood events on overweight status can therefore lead to overestimation of the effect of specific events ${ }^{25-27}$. Whether accumulation of adverse life events influences overweight measures already in childhood or whether changes in weight status emerge later in life is still unclear. Therefore, our systematic review investigates whether accumulation of adverse life events is related to measures of overweight in children.

\section{Methods}

This systematic review and meta-analysis is registered in PROSPERO (registration number CRD42014014927, http://www.crd.york.ac.uk/PROSPERO/)

\section{Search strategy}

A systematic search of MEDLINE, EMBASE, PsycINFO and CINAHL was performed (last search date 18 February 2015). The three search strings consisted of index terms and keywords related to 1) life events, adversities and stress, 2) (childhood) overweight/obesity and overweight measures (e.g. body mass index (BMI), waist circumference, waist-to-hip ratio, waist-to-height ratio) and 3) children, adolescents, teens and youth (see Supporting Information S1 for the search strategy).

\section{Study selection}

Articles were eligible for this systematic review if they met the following criteria: (1) Study design: cohort, cross-sectional or case-control study. (2) Study population: at least $90 \%$ consisted of children $<18$ years from the general population. Studies enrolling children with illnesses or conditions other than overweight/obesity and studies including only children with overweight/obesity and no control group were excluded. (3) Exposure: A measure containing at least two adverse childhood events in at least two domains (e.g. not only events in one specific domain such as school achievements, housing issues or maternal health). Only exposure measures containing events in at least two domains were included in order to ensure that no studies assessing the relation between just one specific type of adversity and overweight were included this systematic review. Adverse childhood events are defined in this study as events (not caused by medication) arising during childhood (<18 years of age) that can threaten the child's mental or physical well-being ${ }^{9,13,18}$. Studies not focusing on events, but solely assessing (rather) stable aspects of children's lives, such as socio-economic status, were not part of the scope of this systematic review. Studies using an adverse childhood events measure that included multiple adverse childhood events as well as (rather) stable aspects of children's lives were included. (4) Outcome: A measure of 
childhood overweight/obesity. (5) Data presentation: The relation between accumulated adverse life events and childhood overweight measures is presented in a quantitative way. (6) Other: Articles must be full text, peer reviewed and written in English (see Supporting Information S2).

Two authors (LKE and KJEvW) independently determined eligibility of identified articles in a two-step procedure. First, titles and abstracts were screened. Subsequently, the full text of all potentially eligible articles was screened. Finally, references of included articles were screened for eligibility. Discrepancies between the two authors were resolved by discussion. If consensus could not be reached, a decision was made by a third author (NS). If information needed to determine eligibility of the articles was missing, authors of potentially eligible articles were contacted. Duplicates were removed.

\section{Data extraction and methodological quality assessment}

Relevant data with regard to study design, study population, sample size, assessment of exposure and outcome, statistical analysis and study estimates were extracted from all included studies by two independent reviewers (LKE and KJEvW).

There is currently no gold standard for quality assessment of observational studies ${ }^{28}$, but the Newcastle-Ottawa Scale (NOS) ${ }^{29}$ is considered suitable for systematic reviews of these studies ${ }^{30}$. In this systematic review the NOS, adjusted to study-specific requirements, was used to assess the methodological quality of the included studies (see Supporting Information S3). Studies could achieve a maximum of nine stars. For cross-sectional studies, the NOS for cohort studies was used. Since three questions did not apply to cross-sectional studies, they could maximally be awarded six stars. Quality assessment was performed by two authors (LKE and KJEvW) independently. Discrepancies were resolved by consensus. In case of persistent disagreement, a third author (NS) made the final decision. The inter-rater agreement on the items of the methodological quality assessment was evaluated by calculating percentage agreement between the raters and Cohen's kappa.

\section{Statistical analysis}

For the meta-analyses, odds ratios (OR) along with their $95 \%$ confidence intervals $(95 \% \mathrm{Cl}$ ) were used. The ORs represent the odds of children with a higher adverse childhood events score to have overweight/obesity or have a higher BMI score compared to children with a lower adverse childhood events score. In case multiple ORs were reported in one article (because several cut-points for dichotomization of the adverse childhood events score were used), the OR comparing the smallest difference in adverse childhood events score (e.g. comparing a score of 1 vs. 0 instead of 2 vs. 0 ) was used to facilitate comparison with studies using a continuous exposure measure. 
If other risk estimates than ORs were reported, such as correlation coefficients or (un)standardized regression coefficients, these were converted to ORs ( $95 \% \mathrm{Cl}$ ) where possible. This was done using information on the exact point estimate, standard error, $\mathrm{p}$ value/significance level, $t$-value, standard deviation of the exposure or outcome and/or sample size of the study ${ }^{31-35}$. When the estimate(s) could not be converted due to insufficient information, authors were contacted to provide the necessary information. If multiple risk estimates within one study could be converted, we selected the estimate (in order of importance) (1) adjusted for gender, socio-economic status (SES), ethnicity and/or age, (2) presenting the relation between exposure and outcome most compatible with the relation investigated in other studies, (3) based on the largest sample size, and finally (4) measured at the latest point in time. When odds ratios were reported for boys and girls separately, both were included in the meta-analysis.

The meta-analysis was performed using STATA (Stata, College Station, TX). A randomeffects model was used to pool the risk estimates because of variations in study population, exposure assessment and adjustment for covariates between studies ${ }^{31}$. Estimates of longitudinal and of cross-sectional and case-control studies were pooled separately. Heterogeneity was assumed to be present if the $\mathrm{I}^{2}$-statistic exceeded $50 \%$ or when the chisquared test was statistically significant $(p<0.10)^{31}$. Heterogeneity was explored using subgroup analyses and univariate meta-regressions ${ }^{31}$. Subgroup analyses were performed for: (1) type of outcome measurement (i.e. overweight/obesity status vs. BMI), (2) type of exposure measurement (i.e. continuous vs. categorical), (3) mean age at outcome assessment (0-6 years, $>6-12$ years and $>12-18$ years), (4) time period included in adverse childhood events assessment (i.e. child's lifetime vs. $\leq 2$ year), and (5) whether the estimate was adjusted for gender, SES, ethnicity and/or age (yes/no). Meta-regressions were performed if $\geq 10$ studies could be included ${ }^{31}$. A significance level of $p<0.05$ was used. To investigate the presence of publication bias, a funnel plot of the log odds ratio against its standard error was produced. Egger's test was used to test funnel plot asymmetry if $\geq 10$ studies could be included ${ }^{36,37}$. As level of significance $p<0.10$ was used.

\section{Results}

The search identified 5402 articles of which 332 were screened full-text and finally 18 articles were included in the systematic review. These 18 articles contained information on 16 distinct studies, including 2 studies with longitudinal results ${ }^{38,39}, 8$ studies with crosssectional results ${ }^{40-47}, 3$ studies (5 articles) with longitudinal as well as cross-sectional results $^{48-52}$ and 3 case-control studies (Figure 1$)^{53-55}$. 


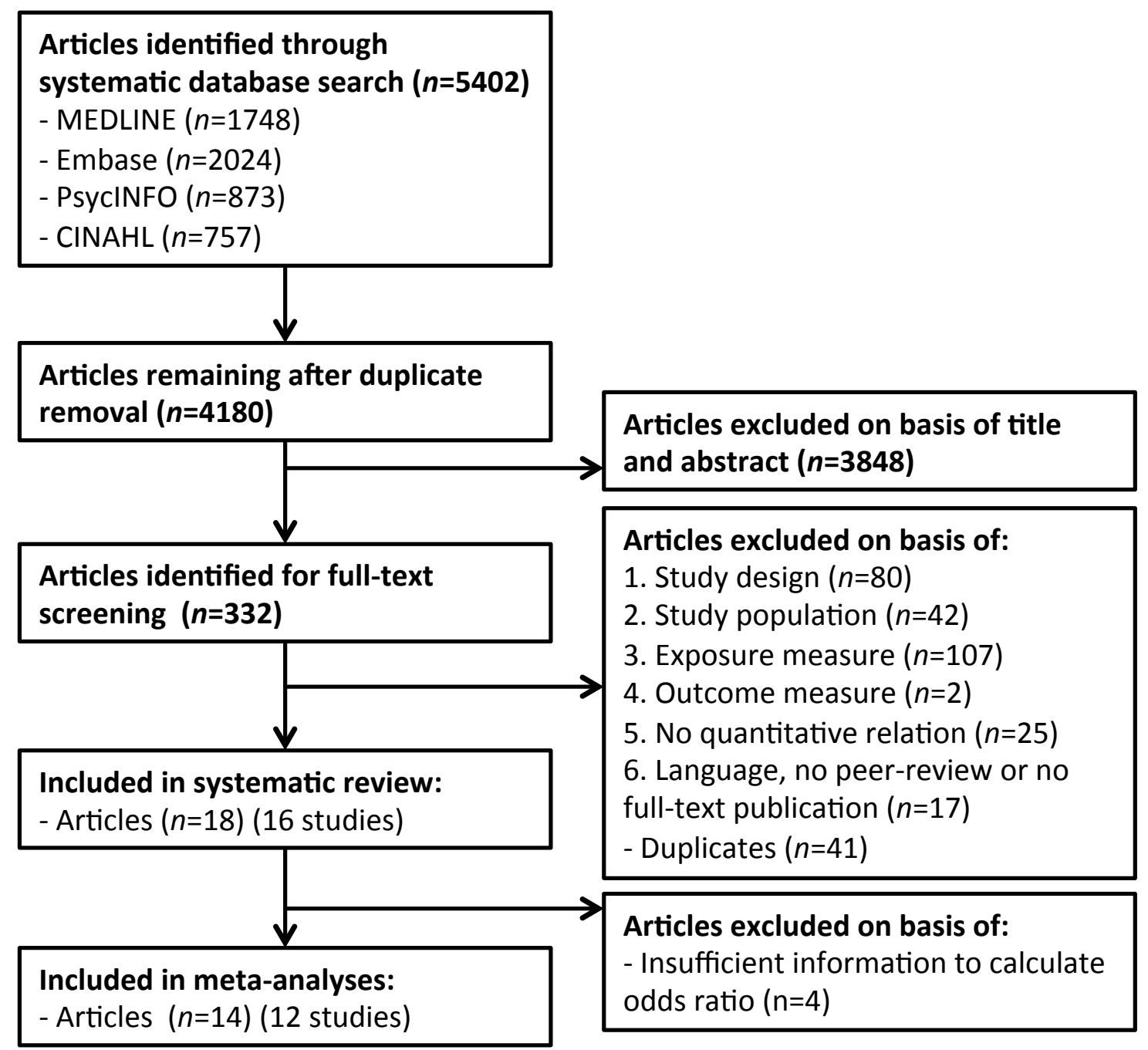

Figure 1. Flow chart of study inclusion

The study characteristics of the included articles are summarized in Table 1 . Three articles reported both cross-sectional and longitudinal results ${ }^{49,50,52}$. Most studies were performed in children between 7 and 13 years ${ }^{40-44,47-55}$, with the exception of two studies in early childhood (i.e. $\leq 5$ years) ${ }^{39,46}$ and two studies in late adolescence (i.e. $\geq 15$ years) ${ }^{38,45}$. The percentage of females in 13 of the included studies ranged between $45 \%$ and $57 \%$ $3844,46-52,55$. Two studies only included boys ${ }^{45,53}$ and in one study the gender distribution of the study population was not described ${ }^{54}$. We observed heterogeneity in the measurement of adverse childhood events. Different measurement tools were used, measuring different numbers of adverse childhood events over different time periods of the child's life. Further, different informants (e.g. the child, mother or parent) reported on the adverse life events that had occurred to either the child, the family of the child and/or the mother of the child. Although all studies generated a sum score reflecting the level of adversity the children had 
experienced, the way in which these scores were created (e.g. as simple sum scores, weighted sum scores, combined with stable aspects, such as socio-economic status, marital status and housing issues, or not) differed between studies. Despite the heterogeneity, there was overlap in the types of adverse childhood events assessed in the different studies. The assessed events in the different studies can roughly be divided into 34 types of adverse childhood events that, except for five events, were all assessed by more than one study (see Supporting Information S4).

There was homogeneity with regard to the outcome. All studies used overweight/obesity status ${ }^{38,39,41,46,52,53}$ or BMI $1^{40,42-45,47-52,54,55}$ as overweight measure. In most studies, overweight was objectively determined ${ }^{38-40,42,44-55}$. One study used selfreported overweight data ${ }^{41}$ and one study did not clearly describe the assessment method used $^{43}$. In addition to reporting on the relation between accumulation of adverse childhood events and BMI, six studies also reported on the association between accumulation of adverse childhood events and other overweight measures, such as waist circumference, waist-to-hip ratio, waist-to-height ratio, body fat percentage and/or skinfold thickness ${ }^{42,44,45,47,50,51}$. The magnitude and direction of each of these estimates was comparable to the magnitude and direction of the estimates of the relation with BMI.

\section{Methodological quality}

The methodological quality of the included studies is presented in Table 2 and Table 3. The methodological quality varied from four to six stars for longitudinal studies, one to three stars for cross-sectional studies and three to four stars for case-control studies. Most methodological flaws ( $>75 \%$ of the studies did not score positively on this item) in longitudinal and cross-sectional studies were found for (1) (description of) the representativeness of the exposed cohort of the population under investigation $193 \%$ of the studies), (3) ascertainment of exposure (often based on written self-report instead of an interview) (93\% of the studies), (6) adjustment for SES, ethnicity and age (80\% of the studies) and (9) (description of) the adequacy of follow-up of cohorts (all of the studies). For casecontrol studies most methodological flaws ( $>75 \%$ of the studies did not score positively on this item) were found for (2) (description of) the representativeness of cases of the population under investigation, (6) adjustment for SES, ethnicity and age (7) ascertainment of exposure (often based on written self-report instead of an interview) and (9) (description of) non-response rate of cases and controls (all of the studies for all four items). The interrater agreement on the items of the methodological quality assessment was very good (overall agreement 89\% (118/132), Cohen's kappa 0.86). 


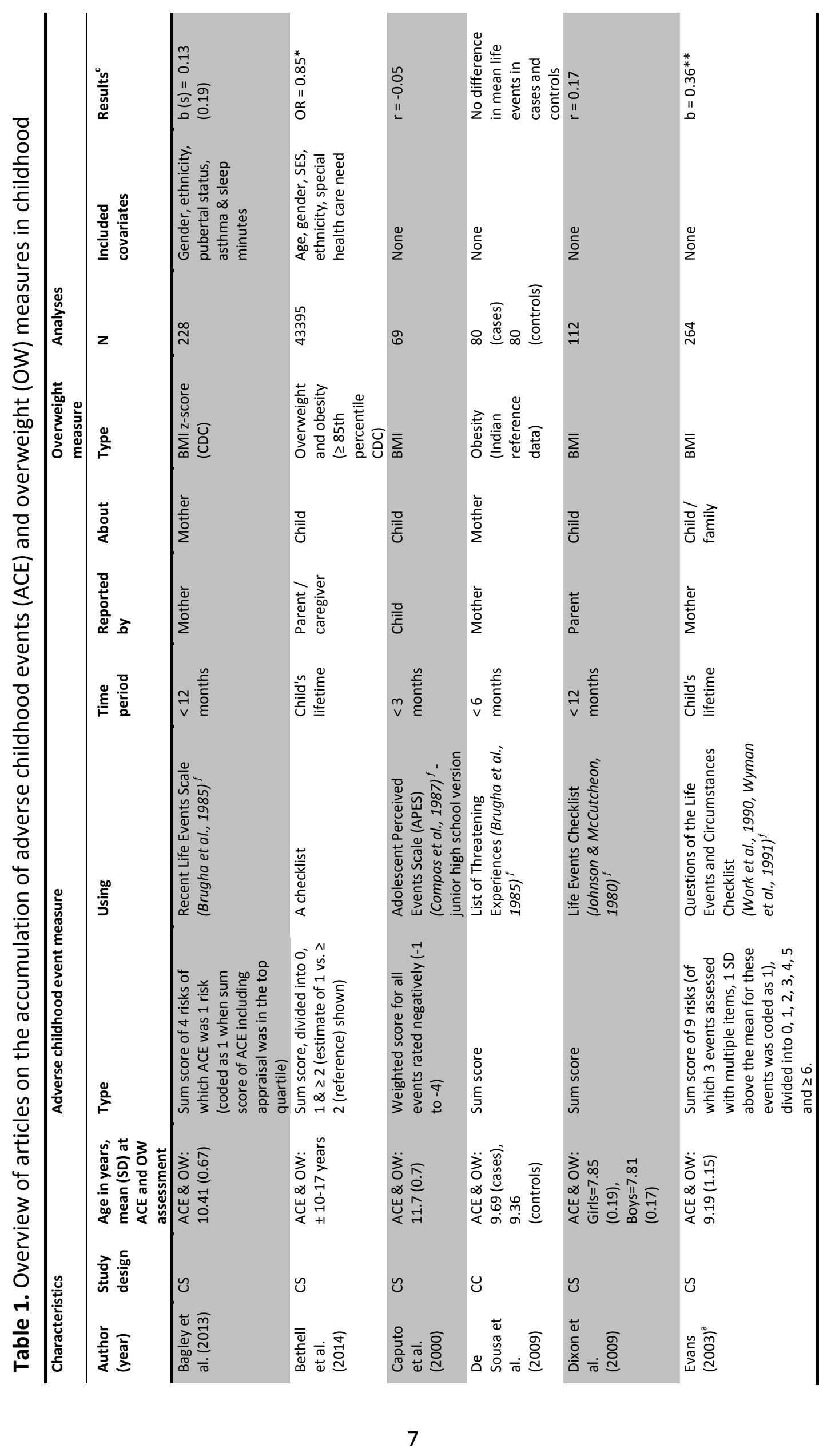




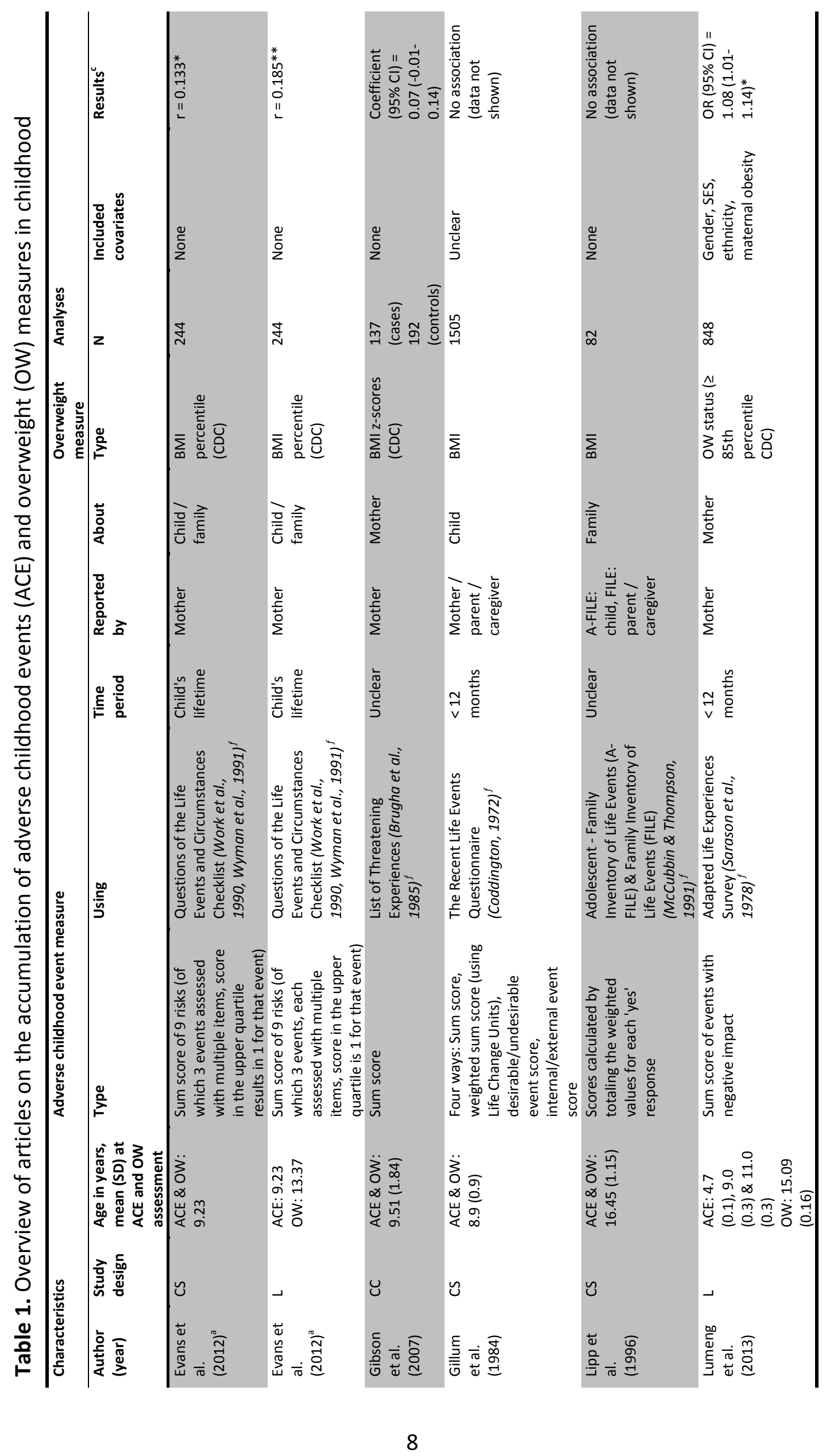




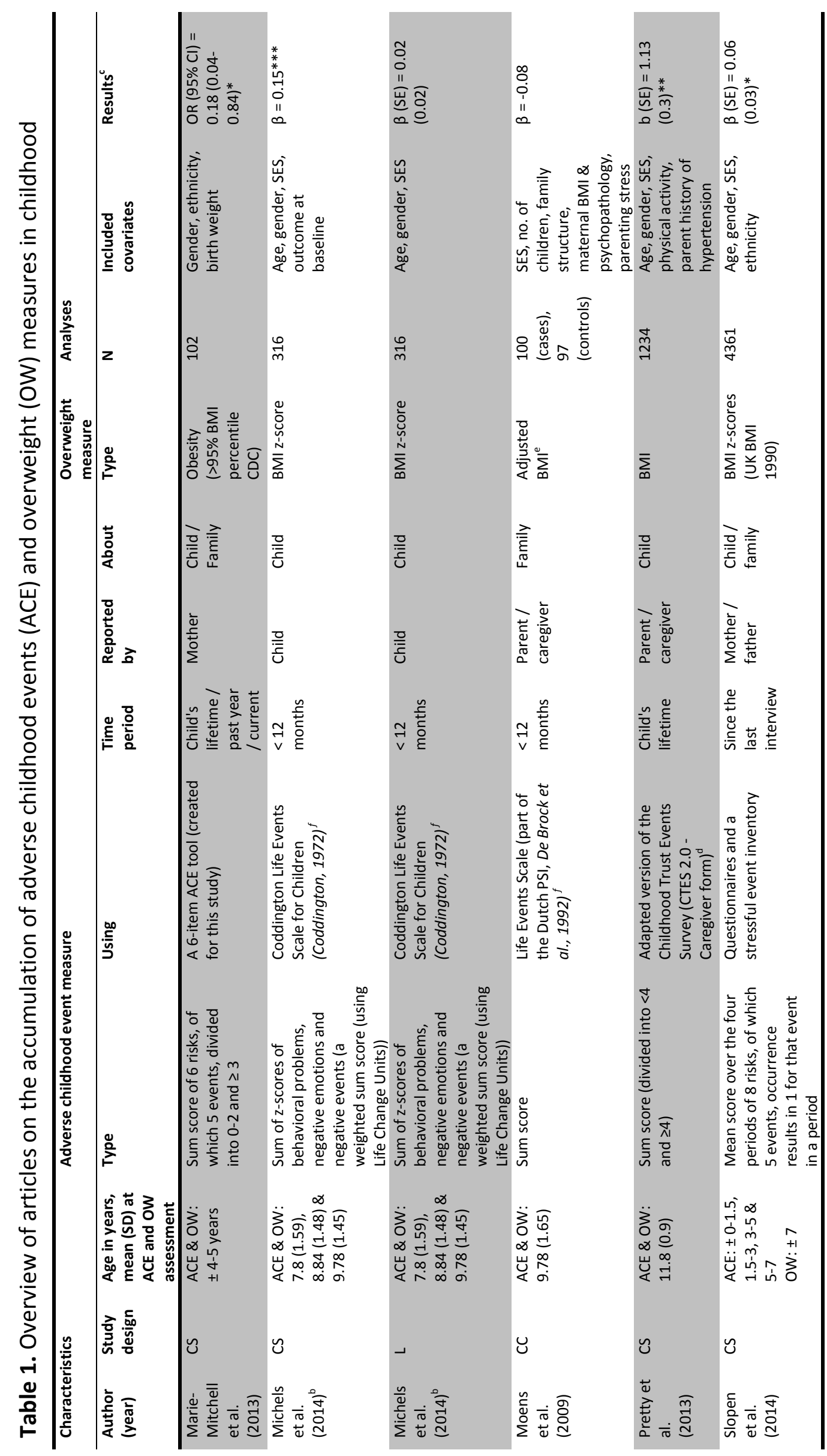




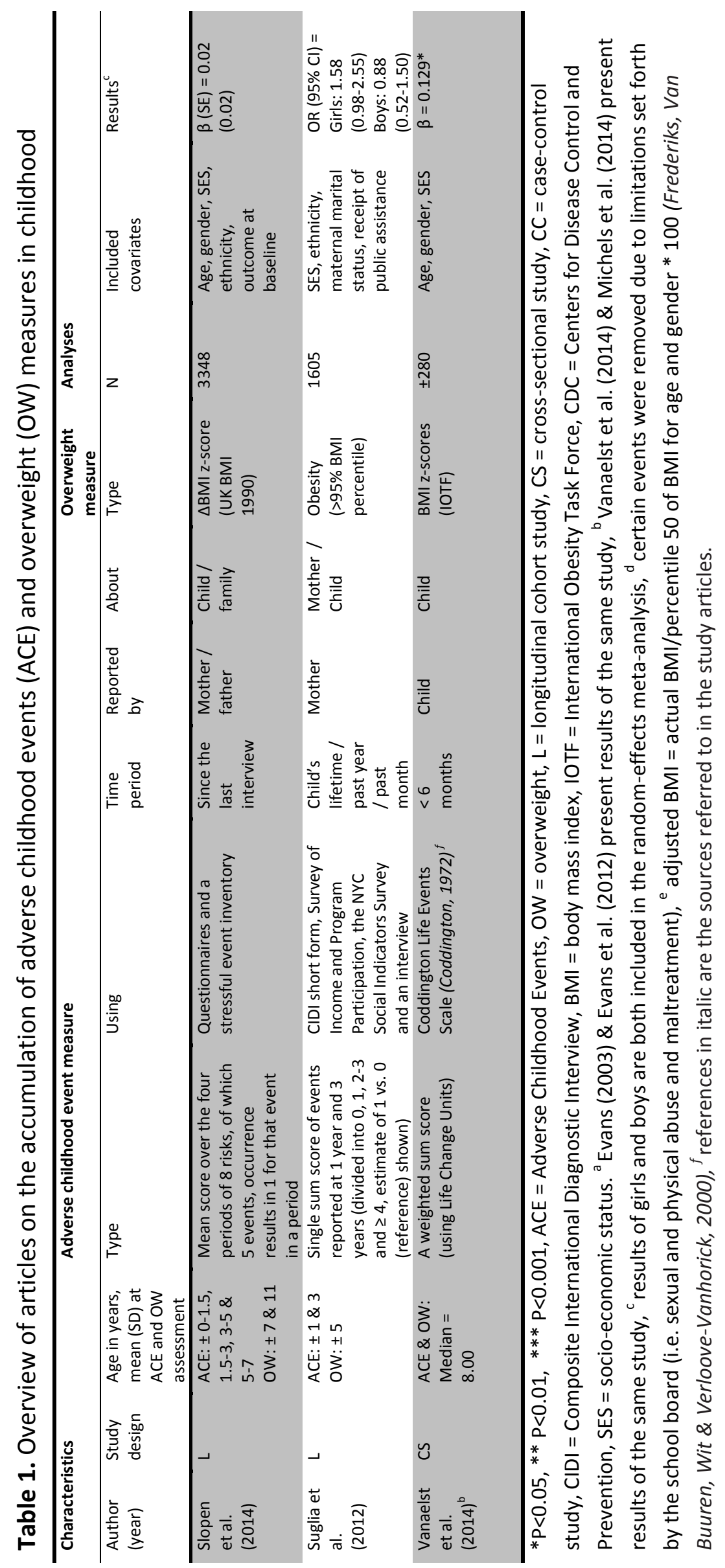




\section{Association between accumulation of adverse childhood events and overweight}

Pooling the results of the five longitudinal studies showed a positive association between accumulated adverse life events and overweight measures in childhood $(\mathrm{OR}(95 \% \mathrm{Cl})=1.12$ (1.01-1.25); $I^{2}=45.2 \%, p=0.10$ ) (Figure 2). The results of four cross-sectional and case-control studies could not be included in the meta-analysis due to insufficient information to recalculate reported estimates into $\mathrm{ORs}^{44,45,53,54}$. The results of the remaining cross-sectional and case-control studies were heterogeneous $\left(I^{2}=52.0 \%, p=0.027\right)$ (Figure 2$)$. Subgroup analyses showed that the study results of 5 subgroups were homogeneous according to our heterogeneity criteria (Table 4). These were the results of studies using a continuous overweight measure (pooled OR $(95 \% \mathrm{Cl})=1.34(1.11-1.62)$ ), studies using a continuous adverse childhood events measure (pooled OR $(95 \% \mathrm{Cl})=1.31(1.01-1.70))$, studies in children between $>6-12$ years of age (pooled OR $(95 \% \mathrm{Cl})=1.34(1.11-1.62))$, studies assessing adverse childhood events in the past 0-2 years (pooled OR $(95 \% \mathrm{Cl})=1.23(0.95-$ 1.58)) and studies that did not adjust for gender, SES, ethnicity and/or age (pooled OR $(95 \% \mathrm{Cl})=1.59(0.98-2.57))$. Meta-regressions of the cross-sectional and case-control studies were only possible for type of outcome measurement, type of exposure measurement, the mean age of the study population and whether studies were adjusted for gender, SES, ethnicity and/or age or not. Based on the univariate meta-regression analyses, we could not explain the heterogeneity in the study results (Table 4).

\section{Publication bias}

Visual inspection of the funnel plot of longitudinal studies and the funnel plot of crosssectional and case-control studies included in the meta-analysis indicated that publication bias was unlikely (Figure 3). The result of the Egger's test for cross-sectional and casecontrol studies was in line with the visual inspection $(p=0.63)$. Less than 10 longitudinal studies were included, therefore funnel plot asymmetry was not statistically tested for longitudinal studies ${ }^{37}$.

\section{Discussion}

In this systematic review and meta-analysis, we investigated the available evidence for a relation between accumulation of adverse life events and overweight measures in childhood. In longitudinal studies, we found a positive relation between accumulation of adverse childhood events and overweight measures. The results of cross-sectional and casecontrol studies were heterogeneous, but with the exception of one study all showed either a positive or a neutral association. Further, the majority of homogeneous subgroups showed a positive pooled estimate. Thus, both types of studies indicated the existence of a positive 


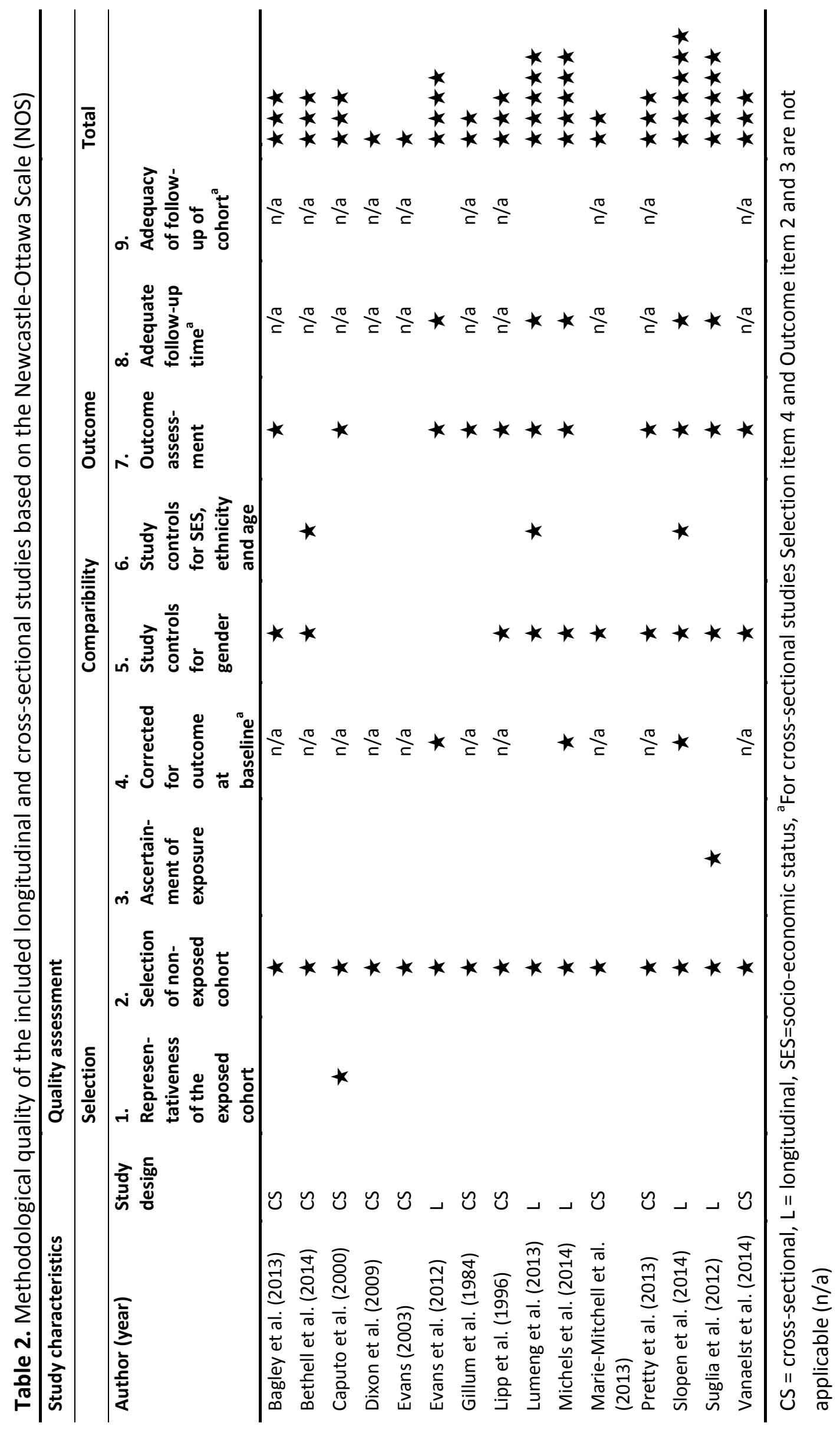




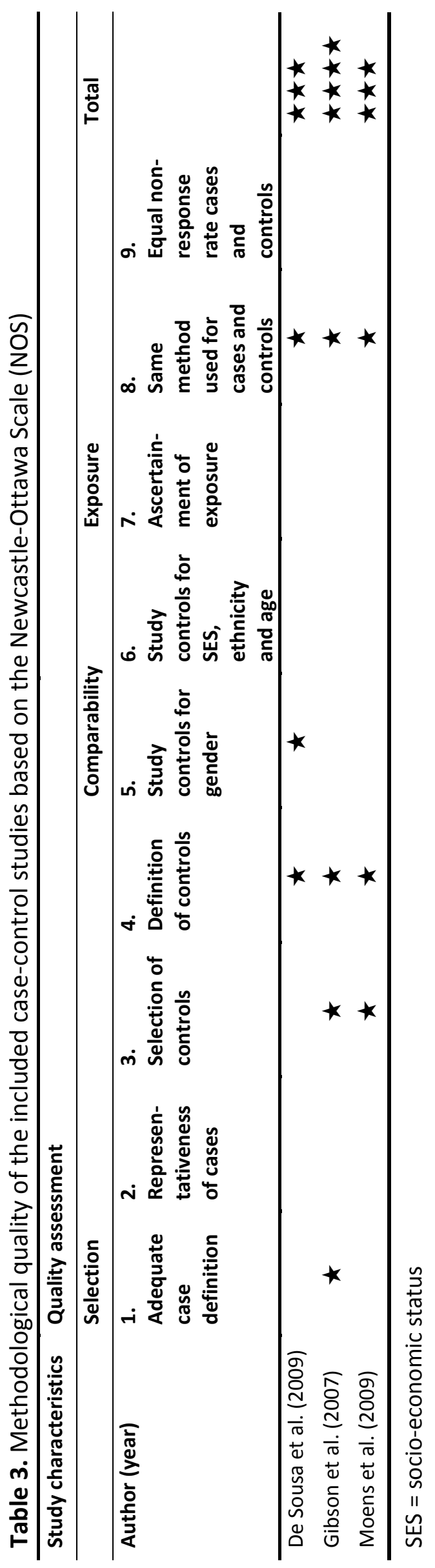


A. Longitudinal studies

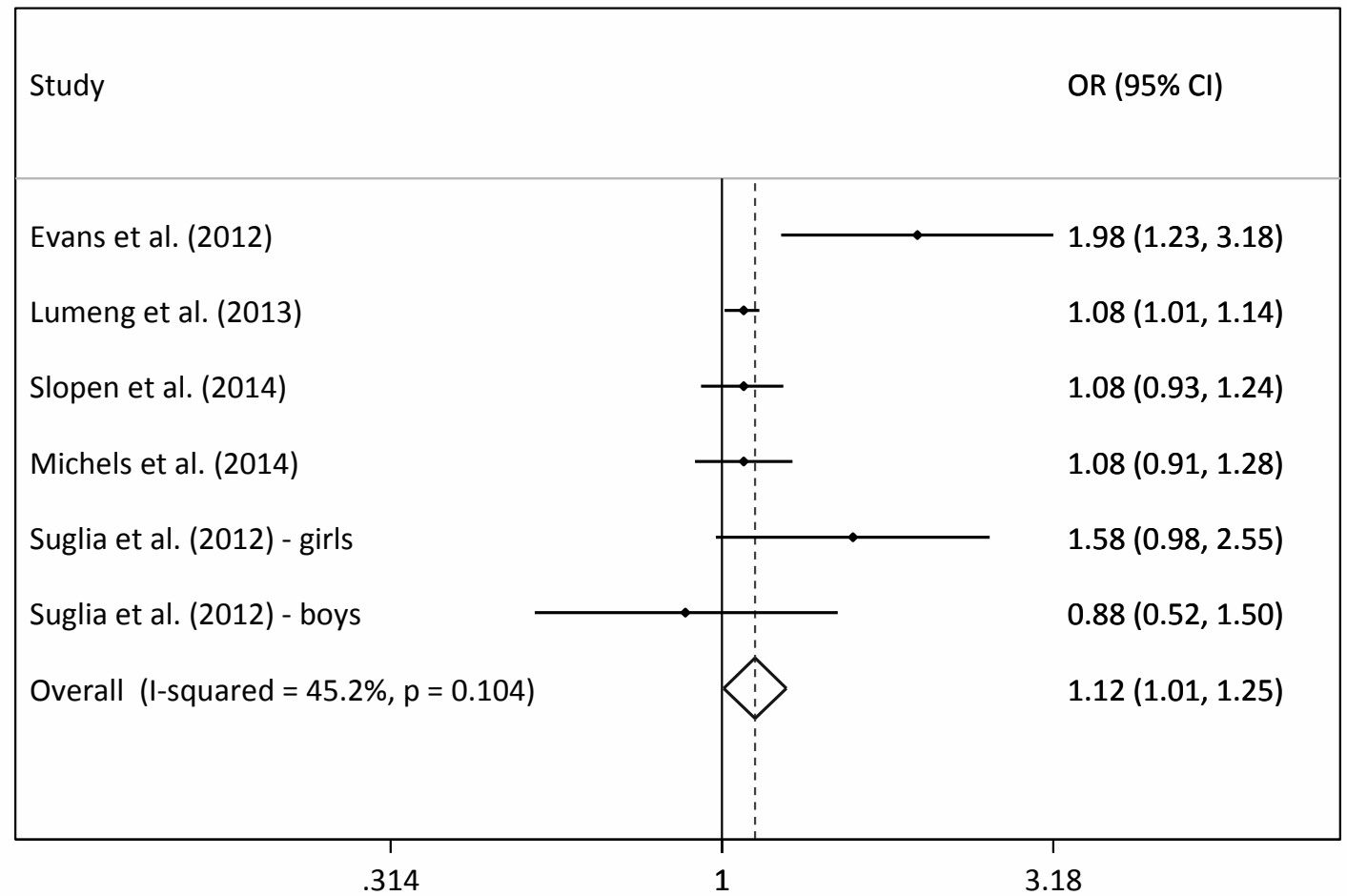

B. Cross-sectional and case-control studies

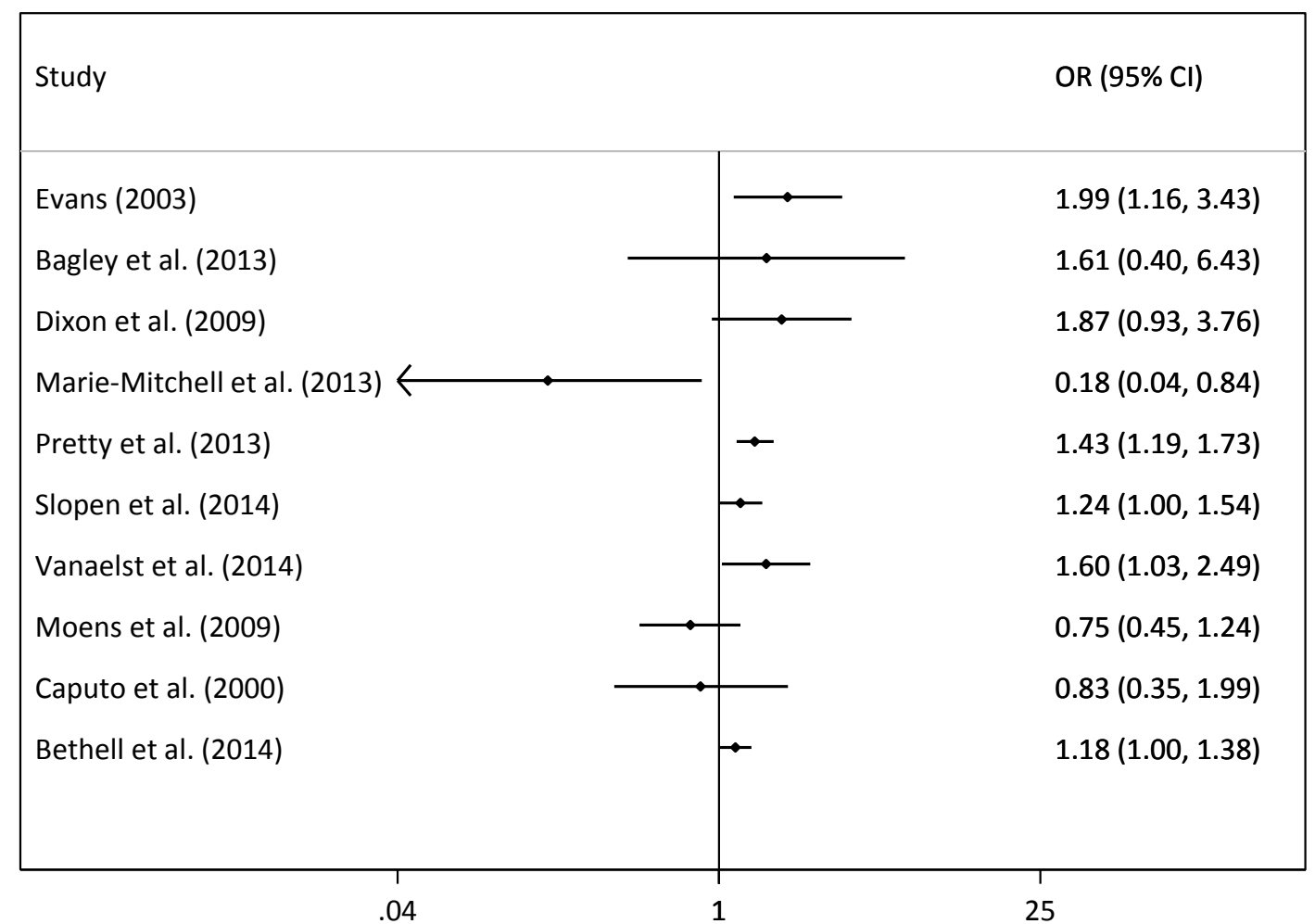

Figure 2. Forest plot of (A) longitudinal studies and (B) cross-sectional and case-control studies included in a random effects meta-analysis. 
Table 4. Subgroup analyses and univariate meta-regressions (if $\geq 10$ studies) of crosssectional and case-control studies included in the meta-analysis

\begin{tabular}{|c|c|c|c|c|c|}
\hline Variable & $\begin{array}{l}\text { No. of } \\
\text { estimates }^{a}\end{array}$ & OR (95\%Cl) & $I^{2}(\%)$ & $\begin{array}{l}\text { p-value } \\
\text { heterogeneity }\end{array}$ & $\begin{array}{l}\text { p-value } \\
\text { meta- } \\
\text { regression }\end{array}$ \\
\hline Overall & 10 & $1.27(1.06,1.52)$ & 52.0 & 0.027 & \\
\hline 1. Outcome measure & & & & & 0.313 \\
\hline Continuous & 8 & $1.34(1.11,1.62)$ & 35.0 & 0.149 & \\
\hline Categorical & 3 & $1.14(0.89,1.47)$ & 66.8 & 0.049 & \\
\hline 2. Exposure measure & & & & & 0.718 \\
\hline Continuous & 7 & $1.31(1.01,1.70)$ & 40.4 & 0.122 & \\
\hline Categorical & 3 & $1.19(0.85,1.66)$ & 76.9 & 0.013 & \\
\hline 3. Mean participant age & & & & & 0.940 \\
\hline $0-6$ years & 1 & $0.18(0.04,0.82)$ & $\mathrm{n} / \mathrm{a}$ & $\mathrm{n} / \mathrm{a}$ & \\
\hline$>6-12$ years & 8 & $1.34(1.11,1.62)$ & 35.0 & 0.149 & \\
\hline$>12-18$ years & 1 & $1.18(1.00,1.39)$ & $\mathrm{n} / \mathrm{a}$ & $\mathrm{n} / \mathrm{a}$ & \\
\hline 4. Recall period events & & & & & $\mathrm{n} / \mathrm{a}$ \\
\hline Child's lifetime & 3 & $1.36(1.10,1.69)$ & 57.9 & 0.093 & \\
\hline$\leq 2$ years & 6 & $1.23(0.95,1.58)$ & 31.9 & 0.196 & \\
\hline 5. Adjusted for gender, & & & & & 0.372 \\
\hline \multicolumn{6}{|l|}{ SES, ethnicity and/or age } \\
\hline Yes & 7 & $1.21(1.00,1.47)$ & 57.0 & 0.030 & \\
\hline No & 3 & $1.59(0.98,2.57)$ & 33.0 & 0.225 & \\
\hline
\end{tabular}

$\mathrm{OR}=$ odds ratio, $\mathrm{Cl}=$ confidence interval, $\mathrm{SES}=$ socio-economic status, $\mathrm{n} / \mathrm{a}=$ not applicable (there were $<10$ studies in the comparison). ${ }^{\text {a }}$ The number of estimates can differ per variable, because (I) in some studies multiple relations are presented and (II) not all studies report information on the factors used in the meta-regressions and subgroup analyses.

relation between accumulation of adverse life events and overweight measures: the more adverse life events children experience, the higher their relative weight.

Subgroup analyses revealed that study results of cross-sectional and case-control studies (1) using a continuous overweight measure, (2) using a continuous adverse childhood events measure and (3) assessing the relation between adverse childhood events and overweight measures in children between $>6-12$ years were homogeneous and generated a positive pooled estimate. This shows that accumulation of adverse childhood events is related to higher measures of BMI, that it indeed is the number of adverse childhood events that is positively associated with higher overweight measures and that the positive relation between accumulation of adverse childhood events and overweight measures is present in primary school children. There was one cross-sectional study that was performed in children $<6$ years and this was the only study to show a negative 
A. Longitudinal studies

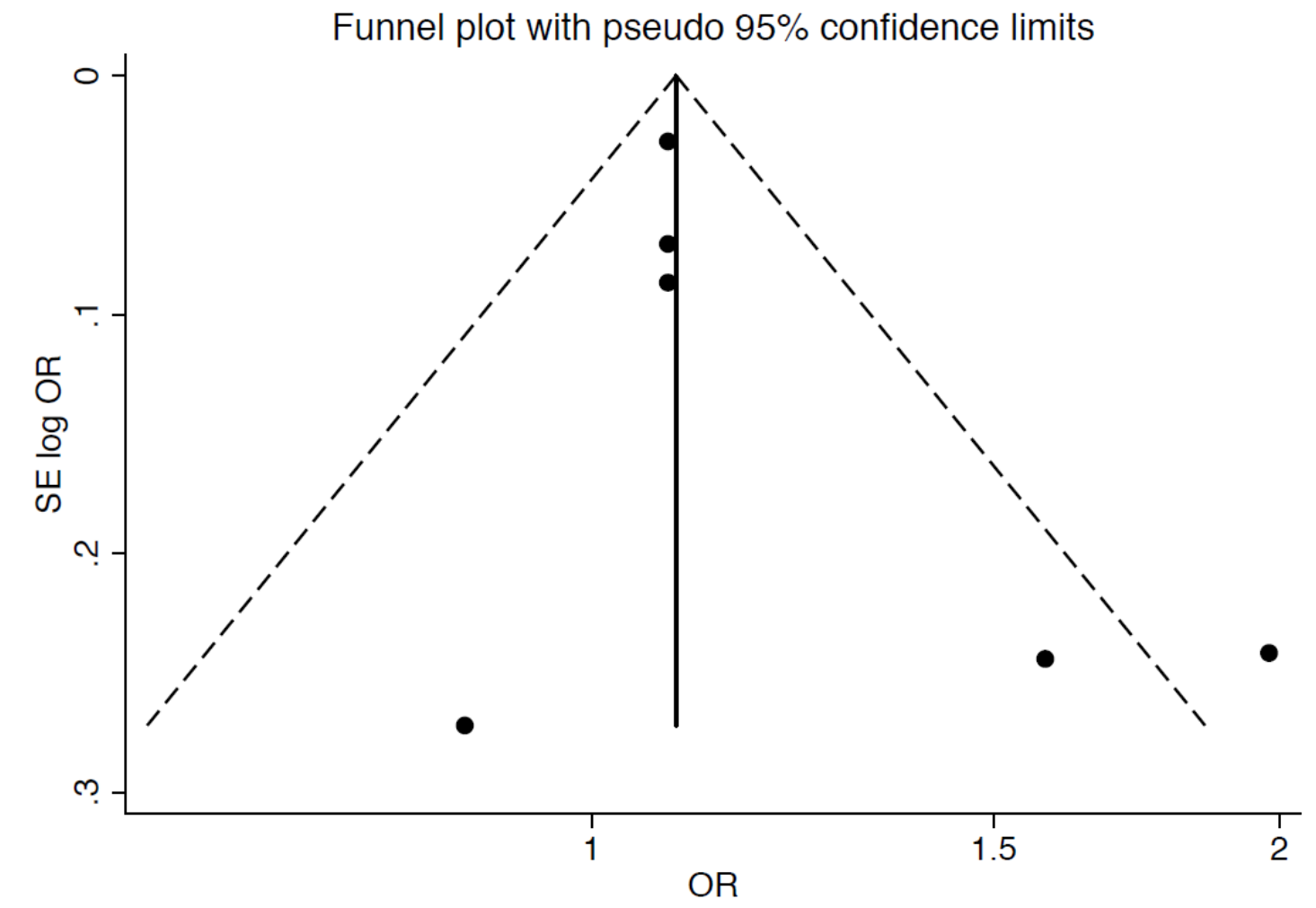

B. Cross-sectional and case-control studies

Funnel plot with pseudo $95 \%$ confidence limits

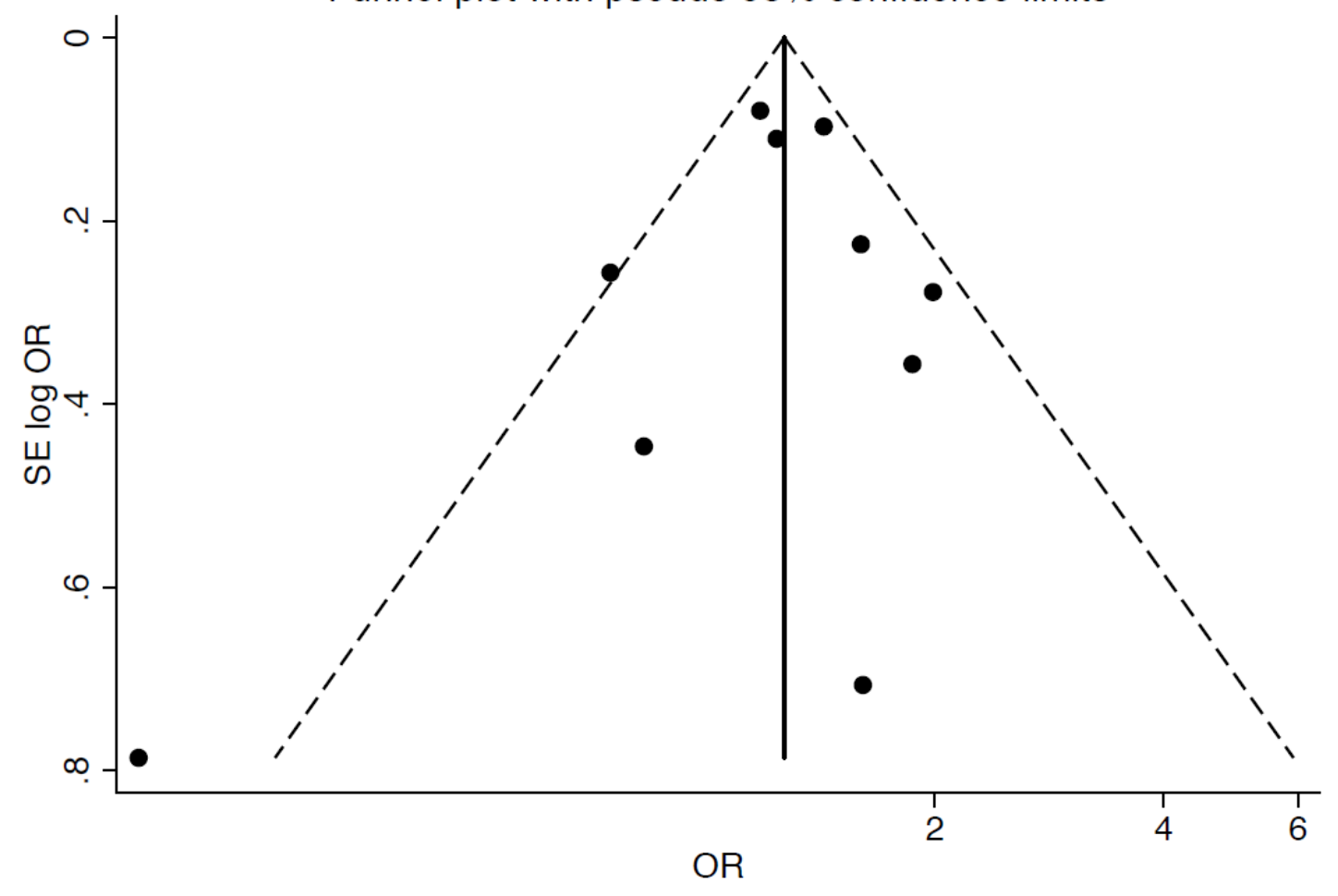

Figure 3. Funnel plot of (A) longitudinal studies and (B) cross-sectional and case-control studies included in the meta-analysis. 
association between accumulation of adverse childhood events and overweight, suggesting that the relation might change from negative to positive over time ${ }^{46}$.

The subgroup analyses further revealed that studies (1) assessing adverse childhood events in the past 0-2 years and (2) not adjusting for gender, SES, ethnicity and/or age, were homogeneous and generated a non-significant pooled estimate. Differences in overweight (measures) in response to adverse childhood events might thus take longer than 0-2 years to develop. This seems to be confirmed by the fact that the pooled estimate of longitudinal studies, $80 \%$ of which have follow-up periods of $\geq 2$ years, is positive. The subgroup of studies not adjusting for any of the specified covariates included only 3 studies of which 1 study of fair methodological quality ( 3 stars) and 2 studies of low quality ( 1 star), limiting our ability to draw firm conclusions about the association within this subgroup.

The positive association identified in this study indicates that children experiencing more acute adversity are more prone to have a higher BMI and develop overweight and obesity than children experiencing less acute adversity. This is in line with the positive association between chronic adversity, e.g. low socio-economic status and poor family functioning, and higher BMI and risk of overweight and obesity identified in previous research ${ }^{11-13}$. Children who are exposed to more adversity have a lower chance of a healthy weight. Additionally, they are probably more likely to have other adverse health conditions

as well ${ }^{41,52}$. Therefore, it is very important to monitor accumulation of events and changes in the social situation of children and their family when children visit the well-child clinic or regular medical care facilities. Early detection of such accumulation can facilitate proper referral and is thus likely to result in health gains.

\section{Past research and future recommendations}

In addition to the identification of a positive relation between accumulation of adverse life events and overweight measures in childhood, another important finding of this systematic review is that there is heterogeneity in the measurement of adverse life events between the included studies. Different studies used different measurement tools to assess adverse childhood events. These included different types of adverse childhood events, different numbers of adverse childhood events and different recall periods. Further, they addressed different people (e.g. the child or parent) and asked them to report on adverse life events in the lives of different actors (e.g. the child or his/her family members). Finally, the adverse childhood events score was constructed in different ways in different studies and sometimes included other, more stable, stressors as well. Researchers investigating the relation between accumulation of adverse life events and overweight measures in 
childhood are therefore recommended to consider three aspects carefully in future research.

The first aspect to consider is which measurement tool to use or, alternatively, which and how many adverse childhood events to include in their study. Currently, the most widely applied tool in this research area for measuring adverse life events in children is the Coddington Life Events Scale and the most widely applied tool for measuring adverse life events in mothers is the List of Threatening Experiences ${ }^{56,57}$. Both tools are easily retrievable and found to be valid ${ }^{50,58}$. The use of these tools is therefore encouraged. Alternatively, when researchers consider existing tools to be unsuitable for their research, they can construct their own list of adverse childhood events. These researchers are encouraged to look at past research and existing scales to make sure they include all relevant (types of) adverse childhood events in their list. Further, the number of adverse childhood events in their list should be sufficient (>10 events) in order for the resulting adverse childhood events score to truly reflect which children experienced more (severe) and which children experienced less (severe) adverse life events. Finally, in choosing a measurement tool it is important to consider the implications of measuring adverse events the child experienced vs. adverse events other family members experienced and the implications of the informant used to report on these events. A child only reports on events of which it is aware, whereas other informants may also report on events of which the child is unaware. This is especially true when family members are asked to report on events in their (families) life instead of the child's life. Thus, events reported by children (and their accumulation) may be more strongly related to weight issues than events that occurred to or were reported by family members.

The second aspect that should receive careful consideration is the time period over which participants are asked to recall adverse childhood events. Obviously, the longer the included time period, the less accurate recall is likely to be. However, it is important to keep in mind that weight changes in response to adverse events do not take place overnight. Therefore, a recall period of $\leq 1$ year is strongly discouraged and periods of $\geq 2$ years are advised. Including the child's entire lifetime can also be sensible to get a complete picture of all the adverse life events the child experienced, especially if the informant is the child's mother or parent.

The third recommendation is to not combine adverse life events that occurred to participants within a given time frame with more stable stressors, such as low socioeconomic status and living in a single-parent household, into one exposure measure. These are very different types of stressors and therefore testing the influence of these stressors separately is highly recommended. 
Future research is further recommended to create sum scores of different types of adverse events (such as health events, relationship events or events of abuse) in addition to sum scores of all experienced events and to test the association between these domainspecific sum scores and overweight measures. In this way, future research can shed light on whether it truly is accumulation of all adverse events, rather than accumulation of specific types of events, that is related to overweight measures in children. Previous research in this area has shown that experiencing many adverse family health events was related to overweight in adolescents, whereas experiencing many adverse relationship events was not $^{38}$. Future research is encouraged to examine whether they can replicate these findings in other populations.

\section{Limitations and strengths}

The relatively small number of studies included in this systematic review and the heterogeneity between studies in the measurement of the exposure warrant caution about over interpreting the identified pooled estimates. However, confidence in the pooled estimates is strengthened by the fact that nearly all pooled estimates support the same conclusion; that there is a positive relation between accumulation of adverse life events and overweight measures in childhood. Additionally, for longitudinal studies, results were consistent, no studies were of low methodological quality (all studies obtained 4-6 stars) and publication bias was found to be unlikely.

Other limitations of this systematic review and meta-analysis mainly stem from methodological issues of the included studies. The adverse childhood events measure in all included studies was, at least partly, based on self-report. Although this is almost inevitable in research on the accumulation of adverse childhood events, this could have led to underreporting of events. Recall bias is expected to be limited in the included studies, as the recall period was often short. On the downside, the short recall period limits the range of adverse childhood events participants report and limits the possibility for overweight development in response to adverse childhood events to have taken place. Reverse causality can also not be excluded; it is possible that children become overweight due to the occurrence of adverse events, but it is also possible that children who are overweight are more likely to experience more adverse events in their lives ${ }^{59}$. Moreover, it is possible that the results of our systematic review were confounded by factors that included studies did not correct for. One factor that could confound the identified association is socio-economic status $^{12,13}$. One of the five longitudinal studies in this systematic review and meta-analysis did not correct for socio-economic status ${ }^{49}$. Post-hoc pooling of the estimates of the four longitudinal studies that did correct for socio-economic status ${ }^{38,39,50,52}$ slightly attenuated 
the results, but still resulted in a statistically significant positive pooled estimate (pooled OR $\left.(95 \% \mathrm{Cl})=1.08(1.03,1.14), \mathrm{I}^{2}=0.0 \%, \mathrm{p}=0.558\right)$. This indicated that the association between accumulation of adverse childhood events and overweight identified in this systematic review is not caused by socio-economic status. However, residual confounding by other, unmeasured, factors is still possible.

Strengths of this study are its focus on all studies examining the relation between accumulation of adverse life events and overweight measures in childhood. This has given us the opportunity to clearly set out the variety of adverse childhood events measures used in this research area and the different results these have generated. It has highlighted that only a limited number of studies assessed the relationship between adverse life events and overweight measures in childhood and that longitudinal studies and studies focusing specifically on the accumulation of adverse childhood events rather than accumulation of adversity (i.e. adverse childhood events in combination with (rather) stable aspects of children's lives) are particularly scarce. Additionally, we provided recommendations for future research concerning accumulation of adverse life events and overweight in childhood. Another strength of this study is that we transformed estimates of almost all identified studies on the relation between accumulated adverse life events and overweight in childhood into ORs $(95 \% \mathrm{Cl})$, which enabled us to pool the results of the studies.

\section{Conclusion}

Our systematic review and meta-analysis shows a positive relationship between the number of adverse life events children experience and overweight measures. There is, however, heterogeneity in the methodology of studies examining the relation between accumulation of adverse childhood events and overweight measures. More research, mostly longitudinal, needs to be done on the specific association between accumulation of adverse childhood events and overweight measures. In this future research, researchers should think carefully about which events and event domains to include in their study. Further, as changes in overweight measures take some time to develop recall periods of adverse childhood events and follow-up periods in these studies should not be too short. 


\section{References}

1. Lobstein T, Baur LA, Uauy R. Obesity in children and young people: a crisis in public health. Obes Rev. 2004;5(Suppl 1):4-85.

2. $\quad$ Singh AS, Mulder C, Twisk JWR, Mechelen W van, Chinapaw MJM. Tracking of childhood overweight into adulthood: A systematic review of the literature. Obes Rev. 2008;9(5):474-488.

3. Simmonds M, Llewellyn A, Owen CG, Woolacott N. Predicting adult obesity from childhood obesity: a systematic review and meta-analysis. Obes Rev. 2016;17(2):95107.

4. Lim SS, Vos T, Flaxman AD, et al. A comparative risk assessment of burden of disease and injury attributable to 67 risk factors and risk factor clusters in 21 regions, 19902010: a systematic analysis for the Global Burden of Disease Study 2010. Lancet. 2012;380(9859):2224-2260.

5. World Health Organization. Obesity: preventing and managing the global epidemic. Report of a WHO consultation. World Health Organ Tech Rep Ser. 2000;894:1-253.

6. Llewellyn A, Simmonds M, Owen CG, Woolacott N. Childhood obesity as a predictor of morbidity in adulthood: a systematic review and meta-analysis. Obes Rev. 2015;17(1):56-67.

7. Rokholm B, Baker JL, Sørensen TIA. The levelling off of the obesity epidemic since the year 1999 - a review of evidence and perspectives. Obes Rev. 2010;11(12):835-46.

8. Schönbeck $\mathrm{Y}$, Talma $\mathrm{H}$, van Dommelen $\mathrm{P}$, et al. Increase in prevalence of overweight in Dutch children and adolescents: a comparison of nationwide growth studies in 1980, 1997 and 2009. PLoS One. 2011;6(11):e27608.

9. Gundersen C, Mahatmya D, Garasky S, Lohman B. Linking psychosocial stressors and childhood obesity. Obes Rev. 2011;12(5):e54-e63.

10. Wardle J, Chida Y, Gibson EL, Whitaker KL, Steptoe A. Stress and adiposity: a metaanalysis of longitudinal studies. Obesity (Silver Spring). 2011;19(4):771-8.

11. Halliday JA, Palma CL, Mellor D, Green J, Renzaho AMN. The relationship between family functioning and child and adolescent overweight and obesity: a systematic review. Int J Obes. 2014;38(4):480-93.

12. Shrewsbury V, Wardle J. Socioeconomic status and adiposity in childhood: a systematic review of cross-sectional studies 1990-2005. Obesity. 2008;16:275-284.

13. Slopen N, Goodman E, Koenen KC, Kubzansky LD. Socioeconomic and other social stressors and biomarkers of cardiometabolic risk in youth: a systematic review of less studied risk factors. PLoS One. 2013;8(5):e64418.

14. Pervanidou P, Chrousos GP. Stress and obesity/metabolic syndrome in childhood and adolescence. Int J Pediatr Obes. 2011;6(Suppl 1):21-28.

15. de Vriendt T, Moreno LA, de Henauw S. Chronic stress and obesity in adolescents: scientific evidence and methodological issues for epidemiological research. Nutr Metab Cardiovasc Dis. 2009;19:511-519.

16. Lissau I, Sørensen TI. Parental neglect during childhood and increased risk of obesity 
in young adulthood. Lancet. 1994;343(8893):324-327.

17. Felitti VJ, Anda RF, Nordenberg D, et al. Relationship of childhood abuse and household dysfunction to many of the leading causes of death in adults. Am J Prev Med. 1998;14(4):245-258.

18. Kalmakis KA, Chandler GE. Adverse childhood experiences: towards a clear conceptual meaning. J Adv Nurs. 2014;70(7):1489-501.

19. Hemmingsson E, Johansson K, Reynisdottir S. Effects of childhood abuse on adult obesity: a systematic review and meta-analysis. Obes Rev. 2014;15(11):882-893.

20. Danese A, Tan M. Childhood maltreatment and obesity: systematic review and metaanalysis. Mol Psychiatry. 2013;19:544-554.

21. Vamosi M, Heitmann BL, Kyvik KO. The relation between an adverse psychological and social environment in childhood and the development of adult obesity: a systematic literature review. Obes Rev. 2010;11(3):177-184.

22. Irish L, Kobayashi I, Delahanty DL. Long-term physical health consequences of childhood sexual abuse: a meta-analytic review. J Pediatr Psychol. 2010;35(5):450-61.

23. Bellis MA, Lowey $\mathrm{H}$, Leckenby $\mathrm{N}$, Hughes $\mathrm{K}$, Harrison D. Adverse childhood experiences: retrospective study to determine their impact on adult health behaviours and health outcomes in a UK population. J Public Heal. 2014;36:81-91.

24. D’Argenio A, Mazzi C, Pecchioli L, Lorenzo G Di, Siracusano A, Troisi A. Early trauma and adult obesity: Is psychological dysfunction the mediating mechanism? Physiol Behav. 2009;98(5):543-546.

25. Dong M, Anda RF, Felitti VJ, et al. The interrelatedness of multiple forms of childhood abuse, neglect, and household dysfunction. Child Abus Negl. 2004;28(7):771-784.

26. Kessler RC, McLaughlin KA, Green JG, et al. Childhood adversities and adult psychopathology in the WHO world mental health surveys. Br J Psychiatry. 2010;197(5):378-385.

27. Wells NM, Evans GW, Beavis A, Ong AD. Early childhood poverty, cumulative risk exposure, and body mass index trajectories through young adulthood. Am J Public Health. 2010;100(12):2507-2512.

28. Cortese S, Moreira Maia CR, Rohde LA, Morcillo-Penalver C, Faraone S V. Prevalence of obesity in attention-deficit/hyperactivity disorder: study protocol for a systematic review and meta-analysis. BMJ Open. 2014;4(3):e004541.

29. Wells G, Shea B, O'Connell D, et al. The Newcastle-Ottawa Scale (NOS) for assessing the quality if nonrandomized studies in meta-analyses. [Internet]. 2012. Available from: http://www.ohri.ca/programs/clinical_epidemiology/oxford.asp

30. Zeng $X$, Zhang $Y$, Kwong JSW, et al. The methodological quality assessment tools for preclinical and clinical studies, systematic review and meta-analysis, and clinical practice guideline: a systematic review. J Evid Based Med. 2015;8:2-10.

31. Higgins JPT, Green S. Cochrane handbook for systematic reviews of interventions version 5.1.0 [Internet]. Cochrane Collab. 2011. Available from: http://www.cochrane.org/training/cochrane-handbook

32. Borenstein M, Hedges L V, Higgins JPT, Rothstein HR. Introduction to meta-analysis. 
Wiley New York, NY 2009.

33. Costa BR da, Rutjes AW, Johnston BC, et al. Methods to convert continuous outcomes into odds ratios of treatment response and numbers needed to treat: metaepidemiological study. Int J Epidemiol. 2012;41(5):1445-1459.

34. Peterson RA, Brown SP. On the use of beta coefficients in meta-analysis. J Appl Psychol. 2005;90(1):175-81.

35. Bring J. How to standardize regression coefficients. Am Stat. 1994;48(3):209-213.

36. Egger M, Davey Smith G, Schneider M, Minder C. Bias in meta-analysis detected by a simple, graphical test. BMJ. 1997;315:629-634.

37. Sterne JAC, Sutton AJ, loannidis JPA, et al. Recommendations for examining and interpreting funnel plot asymmetry in meta-analyses of randomised controlled trials. BMJ. 2011;342:d4002.

38. Lumeng JC, Wendorf $\mathrm{K}$, Pesch $\mathrm{MH}$, et al. Overweight adolescents and life events in childhood. Pediatrics. 2013;132(6):e1506-1512.

39. Suglia SF, Duarte CS, Chambers EC, Boynton-Jarrett R. Cumulative social risk and obesity in early childhood. Pediatrics. 2012;129(5):e1173-9.

40. Bagley EJ, El-Sheikh M. Familial risk moderates the association between sleep and zBMI in children. J Pediatr Psychol. 2013;38(7):775-784.

41. Bethell CD, Newacheck $P$, Hawes E, Halfon N. Adverse childhood experiences: assessing the impact on health and school engagement and the mitigating role of resilience. Health Aff (Millwood). 2014;33(12):2106-2115.

42. Caputo JL, Gill DL, Tseh W, Jamurtas AZ, Morgan DW. Perceived stress and blood pressure in early adolescent children. Ann Behav Med. 2000;22(1):65-70.

43. Dixon D, Meng H, Goldberg R, Schneiderman N, Delamater A. Stress and body mass index each contributes independently to tumor necrosis factor-alpha production in prepubescent Latino children. J Pediatr Nurs. 2009;24(5):378-88.

44. Gillum RF, Prineas RJ, Gomez-Marin O, Chang PN, Finn S. Recent life events in school children: race, socioeconomic status, and cardiovascular risk factors. The Minneapolis Children's Blood Pressure Study. J Chronic Dis. 1984;37(11):839-851.

45. Lipp EJ, Deane D, Trimble N. Cardiovascular disease risks in adolescent males. Appl Nurs Res. 1996;9(3):102-107.

46. Marie-Mitchell A, O'Connor TG. Adverse childhood experiences: translating knowledge into identification of children at risk for poor outcomes. Acad Pediatr. 2013;13(1):14-19.

47. Pretty C, O'Leary DD, Cairney J, Wade TJ. Adverse childhood experiences and the cardiovascular health of children: a cross-sectional study. BMC Pediatr. 2013;13(2010):208

48. Evans GW. A multimethodological analysis of cumulative risk and allostatic load among rural children. Dev Psychol. 2003;39(5):924-933.

49. Evans GW, Fuller-Rowell TE, Doan SN. Childhood cumulative risk and obesity: the mediating role of self-regulatory ability. Pediatrics. 2012;129(1):e68-e73. 
50. Michels N, Sioen I, Boone L, et al. Cross-lagged associations between children's stress and adiposity. Psychosom Med. 2014;77(1):50-58.

51. Vanaelst B, Michels N, Clays E, et al. The association between childhood stress and body composition, and the role of stress-related lifestyle factors - cross-sectional findings from the baseline ChiBS survey. Int J Behav Med. 2014;21(2):292-301.

52. Slopen N, Koenen KC, Kubzansky LD. Cumulative adversity in childhood and emergent risk factors for long-term health. J Pediatr. 2014;164(3):631-638.

53. Sousa A De. Maternal, child and family factors in childhood obesity. Int J Diabetes Metab. 2009;17(3):111-112.

54. Gibson LY, Byrne SM, Davis EA, Blair E, Jacoby P, Zubrick SR. The role of family and maternal factors in childhood obesity. Med J Aust. 2007;186(11):591-595.

55. Moens E, Braet C, Bosmans G, Rosseel Y. Unfavourable family characteristics and their associations with childhood obesity: a cross-sectional study. Eur Eat Disord Rev. 2009;17(4):315-323.

56. Coddington RD. The significance of life events as etiologic factors in the diseases of children: I - A survey of professional workers. J Psychosom Res. 1972;16:7-18.

57. Brugha $T$, Bebbington $P$, Tennant $C$, Hurry J. The List of Threatening Experiences: a subset of 12 life event categories with considerable long-term contextual threat. Psychol Med. 1985;15(1):189-194.

58. Rosmalen JGM, Bos EH, Jonge P de. Validation of the Long-term Difficulties Inventory (LDI) and the List of Threatening Experiences (LTE) as measures of stress in epidemiological population-based cohort studies. Psychol Med. 2012;42(12):2599608.

59. Foss B, Dyrstad SM. Stress in obesity: cause or consequence? Med Hypotheses. 2011;77(1):7-10. 
Supporting Information 


\title{
Supporting Information S1 - Search strategy
}

\author{
Search term MEDLINE
}

(life change event [MeSH] OR stress, psychological [MeSH] OR child abuse [MeSH] OR adverse event* [tw] OR adverse experience* [tw] OR life trauma [tw] OR life event* [tw] OR life experience* [tw] OR life adversity [tw] OR life adversities [tw] OR stressful event* [tw] OR stressful experience* [tw] OR childhood event* [tw] OR childhood experience* [tw] OR childhood trauma [tw] OR childhood adversity [tw] OR childhood adversities [tw] OR family adversity [tw] OR family adversities [tw] OR family instability [tw] OR life stress* [tw] OR child abuse [tw] OR child maltreatment [tw] OR family conflict* $[\mathrm{tw}])$

AND

(obesity [MeSH] OR pediatric obesity [MeSH] OR obesity OR overweight OR body mass index [MeSH] OR body mass index [tw] OR bmi OR body fat distribution [MeSH] OR body fat [tw] OR skinfold thickness [tw] OR skinfolds OR waist-hip ratio [tw] OR waist hip ratio [tw] OR waist-to-hip ratio [tw] OR waist to hip ratio [tw] OR waist-height ratio [tw] OR waist height ratio [tw] OR waist-to-height ratio [tw] OR waist to height ratio [tw] OR waist circumference [tw])

AND

(child [MeSH] OR child, preschool [MeSH] OR adolescent [MeSH] OR child* OR adolescen* OR teen* OR youth*)

\section{Search term EMBASE}

('life event'/exp OR 'life events scale'/exp OR 'mental stress'/exp OR 'life stress'/exp OR 'child abuse'/exp OR 'adverse event' OR 'adverse events' OR 'adverse experience' OR 'adverse experiences' OR 'life trauma' OR 'life event' OR 'life events' OR 'life experience' OR 'life experiences' OR 'life adversity' OR 'life adversities' OR 'stressful event' OR 'stressful events' OR 'stressful experience' OR 'stressful experiences' OR 'childhood event' OR 'childhood events' OR 'childhood experience' OR 'childhood experiences' OR 'childhood trauma' OR 'childhood adversity' OR 'childhood adversities' OR 'family adversity' OR 'family adversities' OR 'family instability' OR 'life stress' OR 'life stresses' OR 'child abuse' OR 'child maltreatment' OR 'family conflict'/exp OR 'family conflict')

AND

('obesity'/mj OR 'childhood obesity'/exp OR 'abdominal obesity'/exp OR 'diabetic obesity'/exp OR 'morbid obesity'/exp OR 'obesity' OR 'overweight' OR 'body mass'/exp OR 'body mass index' OR 'bmi' OR 'body fat distribution'/exp OR 'body fat' OR 'skinfold thickness' OR 'skinfolds' OR 'waist hip ratio'/exp OR 'waist-hip ratio' OR 'waist hip ratio' OR 'waist-to-hip ratio' OR 'waist to hip ratio' OR 'waist to height ratio'/exp OR 'waist-height ratio' OR 'waist height ratio' OR 'waist-to-height ratio' $O R$ 'waist to height ratio' OR 'waist circumference'/exp OR 'waist circumference')

AND

('child'/mj OR 'toddler'/mj OR 'preschool child'/mj OR 'school child'/mj OR 'adolescent'/mj OR child* OR adolescen* OR teen* OR youth*) 


\section{Search term PsycINFO}

(DE "life experiences" OR DE "experiences (events)" OR DE "early experience" OR DE "life changes" OR DE "child abuse" OR DE "trauma" OR DE "emotional trauma" OR DE "stress" OR DE "psychological stress" OR DE "chronic stress" OR DE "distress" OR DE "family crises" OR DE "family conflict" OR TX adverse event* OR TX adverse experience* OR TX life trauma OR TX life event* OR TX life experience* OR TX life adversity OR TX life adversities OR TX stressful event* OR TX stressful experience* OR TX childhood event* OR TX childhood experience* OR TX childhood trauma OR TX childhood adversity OR TX childhood adversities OR TX family adversity OR TX family adversities OR TX family instability OR TX life stress* OR TX child abuse OR TX child maltreatment OR TX family conflict*)

AND

(DE "obesity" OR DE "overweight" OR TX obesity OR TX overweight OR DE "body mass index" OR TX body mass index OR TX bmi OR TX body fat OR TX skinfold thickness OR TX skinfolds OR TX waist-hip ratio OR TX waist hip ratio OR TX waist-to-hip ratio OR TX waist to hip ratio OR TX waist-height ratio OR TX waist height ratio OR TX waist-to-height ratio OR TX waist to height ratio OR TX waist circumference)

AND

(TX child* OR TX adolescen* OR TX teen* OR TX youth*)

\section{Search term CINAHL}

(MH "life change event" OR MH "life experiences" OR MH "child abuse" OR MH "trauma" OR MH "stress" OR MH "stress, psychological" OR MH "family conflict" OR TX adverse event* OR TX adverse experience* OR TX life trauma OR TX life event* OR TX life experience* OR TX life adversity OR TX life adversities OR TX stressful event* OR TX stressful experience* OR TX childhood event* OR TX childhood experience* OR TX childhood trauma OR TX childhood adversity OR TX childhood adversities OR TX family adversity OR TX family adversities OR TX family instability OR TX life stress* OR TX child abuse OR TX child maltreatment OR TX family conflict* OR MH "Family Inventory of Life Events and Changes" OR MH "Young Adult Family Inventory of Life Events and Strains" OR MH "Adolescent-Family Inventory of Life Events and Changes" OR MH "Schedule of Recent Experience")

AND

(MH "obesity" OR MH "pediatric obesity" OR MH "obesity, morbid" OR TX obesity OR TX overweight OR MH "body mass index" OR TX body mass index OR TX bmi OR TX body fat OR MH "skinfold thickness" OR TX skinfold thickness OR TX skinfolds OR MH "waist-hip ratio" OR TX waist-hip ratio OR TX waist hip ratio OR TX waist-to-hip ratio OR TX waist to hip ratio OR TX waist-height ratio OR TX waist height ratio OR TX waist-to-height ratio OR TX waist to height ratio OR MH "waist circumference" OR TX waist circumference)

AND

(MH "child" OR MH "child, preschool" OR MH "adolescence" OR TX child* OR TX adolescen* OR TX teen* OR TX youth*) 


\section{Supporting Information S2 - Eligibility criteria}

1. Study must be an observational study, a cross-sectional, longitudinal cohort or case-control study.

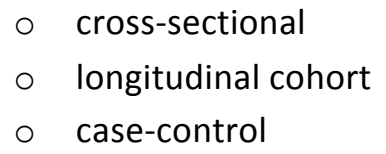

(Qualitative and case studies, randomized controlled trials, intervention studies, experimental studies, validation studies, adverse drug event studies, (systematic) reviews, editorials, letters, dissertations, books, commentaries and meeting abstracts are excluded. Cases in case-control studies must be selected on an overweight measure)

2. Study population consists of human children of the general population of which at least $90 \%$ is $<18$ years of age. (in this period adverse childhood events and (a) measure(s) of overweight must at least be determined once. Children may not be selected for the study based on a medical condition (other than overweight/obesity))

$\square$ exclusion based on (part of the) population being between 18-21 years?

3. Adverse childhood events that occurred before age 18 must be assessed.

(Research with only family/household characteristics included in the adverse events, e.g. socio-economic status, marital status of parents, parental overweight measures, number of household members, number of siblings, family and mealtime practices, is excluded.)

a) At least two events must be assessed in two domains

YES / NO

b) A measure of cumulative adversity, containing at YES / NO least these two events, must be determined.

c) At least two of the included events or the used adverse event checklist/questionnaire/interview must be explicitly named.

(if no examples are given of included events or the assessment method, the study is excluded.) 
d) At least two of the specified events must meet the definition of adverse childhood events*.

(if less than two of the events in the study meet the definition of adverse childhood events of this systematic review, the study is excluded.)

4. At least one of the following outcome measures must be reported (and measured before age 18):

○ BMI

- BMI z-score

o overweight/obesity status

o waist-to-hip ratio

- waist circumference (WC)

o waist-to-height ratio (WHtR)

- sum of skinfolds (SS)

O skinfold thickness

- body fat percentage (BF\%)

- Other overweight measures not solely based on weight (not corrected for height)

$\square$ exclusion based on the use of an outcome measure solely based on weight (not corrected for height)?

5. Relation between a measure of accumulated adverse childhood events and overweight measure(s) must have been tested and the results must be presented quantitatively. (a statement of non-significance of the relation between accumulated adverse childhood events and overweight is sufficient.)

6. Research article must be:
a) In English
b) Peer-reviewed
c) A full-text publication
d) Published before 18-02-2015

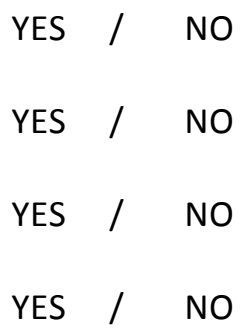

* Adverse childhood events are defined in this study as events (not caused by medication) arising during childhood ( $<18$ years of age) that can threaten the child's mental or physical well-being (Gundersen et al., 2011, Slopen et al., 2013, Kalmakis \& Chandler, 2014).

\section{Study is included / excluded / other (circle)}




\section{Supporting Information S3 - Quality assessment forms}

\section{NEWCASTLE - OTTAWA QUALITY ASSESSMENT SCALE COHORT STUDIES}

Note: A study can be awarded a maximum of one star for each numbered item within the Selection and Outcome categories. A maximum of two stars can be given for Comparability

\section{Selection}

1) Representativeness of the exposed cohort

a) truly representative of the population under investigation (consecutive series with $>90 \%$ of the eligible population recruited or no significant differences with population from which is sampled with regard to gender, SES, ethnicity/race, age)

b) somewhat representative of the population under investigation (consecutive series with $>80 \%$ of the eligible population recruited or only significant differences with population on one of the following variables: gender, SES, ethnicity/race, age)

c) selected group of participants, not representative of the population under investigation

d) no description of the derivation of the cohort or difference with population under investigation

2) Selection of the non-exposed cohort
a) drawn from the same community as the exposed cohort
b) drawn from a different source
c) no description of the derivation of the non-exposed cohort

3) Ascertainment of exposure
a) interview
b) written self-report only (by child/parent/caretaker/other family member)
c) no description

4) Demonstration that outcome of interest was not present at start of study (e.g. no overweight/obesity status at baseline or controlling for outcome at baseline)
a) yes
b) no

\section{Comparability}

1) Comparability of cohorts on the basis of the design or analysis
a) study controls for (or stratifies results according to) gender
b) study controls for SES (e.g. maternal/paternal education, maternal/paternal occupation, family income) AND ethnicity/race AND age, if necessary (e.g. the sample is not completely homogenous on these characteristics)

\section{Outcome}

1) Assessment of outcome
a) independent objective assessment (with standard cut-points (e.g. WHO/CDC/IOTF))
b) (medical) record (with standard cut-points (e.g. WHO/CDC/IOTF))
c) objective assessment or (medical) record with non-standard cut-points (e.g. not WHO/CDC/IOTF)
d) self-report (by child/parent/caretaker/other family member)
e) no description 
2) Was follow-up long enough for outcomes to occur

a) yes, follow-up was $\geq 1$ year

b) no

3) Adequacy of follow up of cohorts

a) complete follow up - all subjects accounted for

b) subjects lost to follow up unlikely to introduce bias - small number lost - > $80 \%$ follow up, or description provided of those lost indicating no differences on the following variables: gender, SES, ethnicity/race, age

c) follow up rate $<80 \%$ and no description of those lost or a description indicating a difference on one of the following variables: gender, SES, ethnicity/race, age

d) no statement 


\section{NEWCASTLE - OTTAWA QUALITY ASSESSMENT SCALE CASE CONTROL STUDIES}

Note: A study can be awarded a maximum of one star for each numbered item within the Selection and Exposure categories. A maximum of two stars can be given for Comparability.

\section{Selection}

1) Adequate case definition

a) yes, based on (medical) records or objective measures (with standard cut-points (e.g. WHO/CDC/IOTF))

b) yes, based on self-report (by child/parent/caretaker/other family member) or objective measures using non-standard cut-points (e.g. not WHO/CDC/IOTF)

c) no description

2) Representativeness of the cases

a) yes, consecutive or obviously representative cases (consecutive series with $>80 \%$ of the eligible population recruited or only significant differences between eligible and recruited sample on one of the following variables: gender, SES, ethnicity/race, age)

b) potential for selection bias or not stated

3) Selection of Controls

a) community controls (recruitment through schools allowed)

b) primary care/hospital controls

c) no description

4) Definition of Controls

a) overweight measures indicating healthy weight (trajectories)

b) no description or not indicating that the child is not a case

\section{Comparability}

1) Comparability of cases and controls on the basis of the design or analysis

a) study matched on or controls for (or stratifies results according to) gender

b) study matched on or controls for SES (e.g. maternal/paternal education, maternal/paternal occupation, family income) AND ethnicity/race AND age, if necessary (e.g. the sample is not completely homogenous on these characteristics)

\section{Exposure}

1) Ascertainment of exposure
a) interview
b) written self-report only (by child/parent/caretaker/other family member)
c) no description

2) Same method of ascertainment for cases and controls
a) yes
b) no

3) Non-Response rate
a) same rate for both groups
b) non respondents described
c) rate different and no designation
d) unclear 


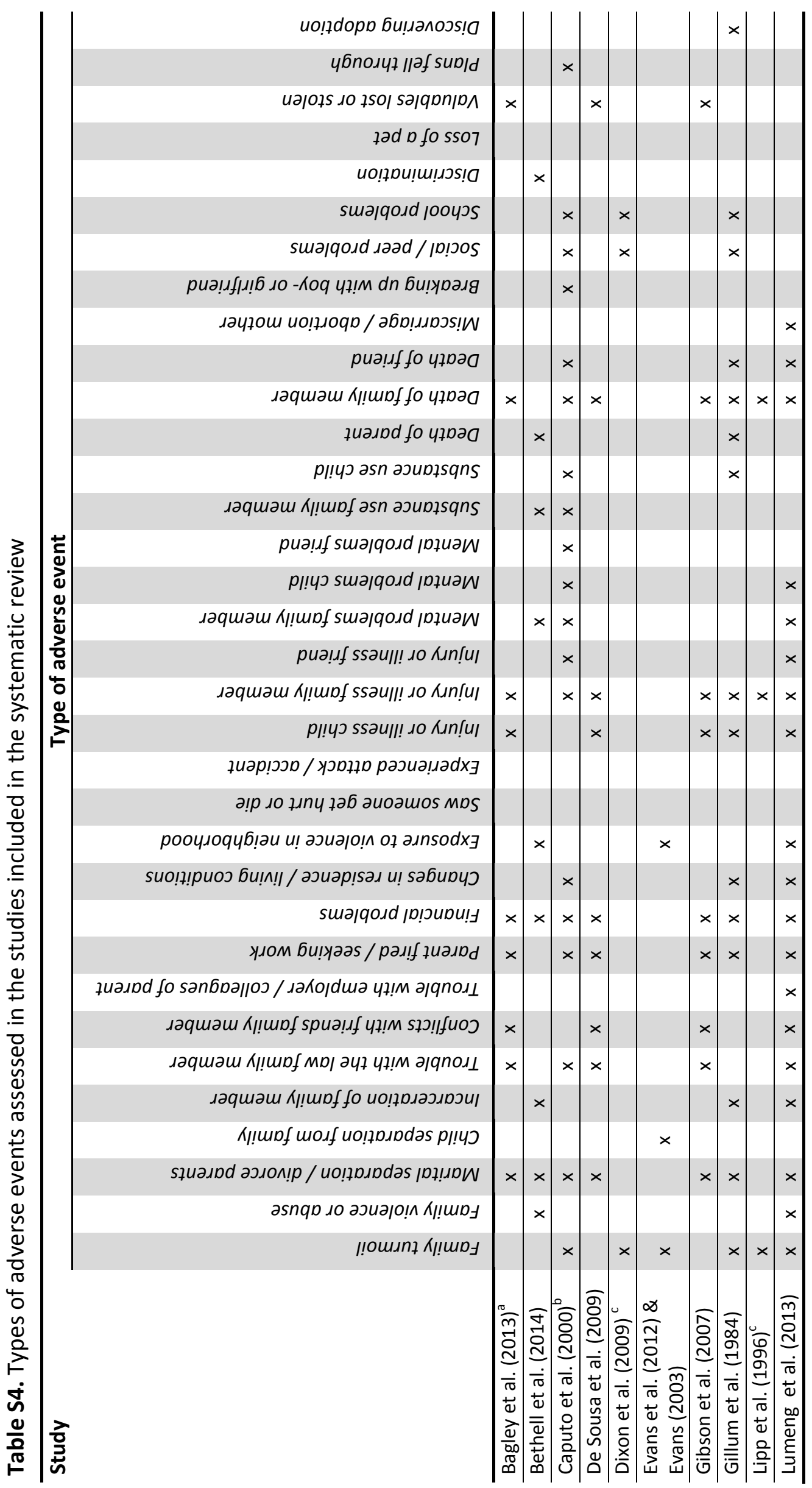




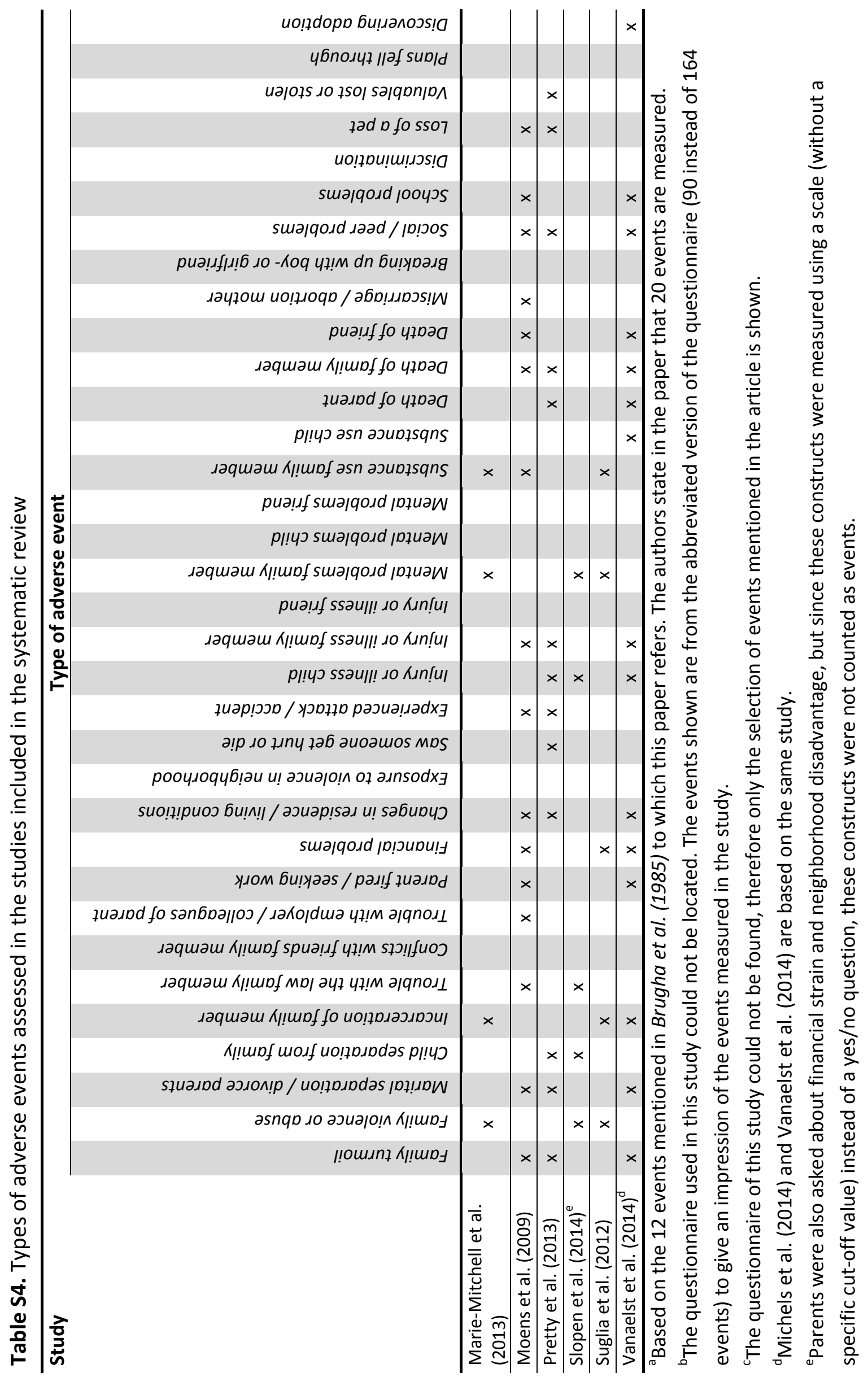

